\title{
Talleres estatales de marfil y dirección honorífica en al-Andalus en época del Califato. El caso de Durrī al-Sagīr
}

\author{
Noelia Silva SANTA-CRUZ \\ Universidad Complutense de Madrid \\ nsilva@ghis.ucm.es
}

Con la aspiración de entroncar con sus ancestros y presentarse como la única dinastía legítima del Islam frente a los Abbasíes ${ }^{1}$, y también frente a sus más inmediatos vecinos norteafricanos, los Fatimíes, los monarcas andalusíes no dudaron desde época emiral en imitar los diferentes sistemas de promoción oficial que los Omeyas orientales habían adoptado tras la creación del Califato en el siglo VI para conferir brillo y esplendor a la institución gobernante. De estos variados mecanismos de propaganda política, uno de los que más había adornado y favorecido tradicionalmente la expresión del poderío regio fue la institución de monopolios del Estado, una medida que comprendía tanto la acunación de moneda como la creación de talleres artísticos especializados ${ }^{2}$.

El célebre historiador Ibn Jaldún hace referencia en su conocida obra Introducción a la historia universal a la capacidad para emitir moneda como uno de los principales emblemas de realeza y signos distintivos de soberanía ${ }^{3}$. Las producciones de la ceca no eran solo un mero instrumento económico, expresión de la fiscalidad del Estado, sino que se concebían y eran potenciadas desde la institución gobernante como una espléndida manera de legitimar y difundir el poder del monarca, al incorporar bien visible en las piezas el nombre del soberano. Ya desde época de 'Abd al-Rahmān I, la casa de la moneda (dār al-sikka) se encontraba establecida en Córdoba, siendo reestructurada por 'Abd al-Rahmān II (822-852), quien mandó erigir para ella unos edificios especializados destinados a dar cobertura al incremento de la producción

1 S. CALVO CAPILLA, "Analogies entre les Grandes Mosquées de Damas et Cordoue: Mythe et Réalité", A. BORRUT y P. M. COBB (eds.), Umayyad Legacies: Medieval Memories from Syria to Spain, Leiden, 2010, pp. 281-282.

2 La propaganda estatal se manifestaba en los territorios del Islam también mediante la alocución o sermón de los viernes en las mezquitas (jutba), en la que se invocaba el nombre del soberano reinante, así como a través de la presencia en la corte de cronista y poetas áulicos que elogiaban al monarca con panegíricos de amplia difusión. Vid. M. A. MARTÍNEZ NÚÑ̃EZ, "Correos y medios de comunicación y propaganda en alAndalus", A. PÉREZ JIMÉNEZ y G. CRUZ ANDREOTTI, Aladas palabras. Correos y comunicaciones en el Mediterráneo, Madrid, 1999, pp. 133-172.

3 IBN JALDÚN, Introducción a la Historia Universal (al-Muqaddima), Edición y traducción de F. RUIZ GIRELA, Córdoba, 2008, libro I, cap. III, apdo. 34, pp. 457-463. 
monetaria registrado durante su mandato ${ }^{4}$. Fue precisamente el cuarto emir omeya quien, en su afán por centralizar la administración estatal, consolidó este organismo consagrado a la acuñación, y estableció por vez primera en al-Andalus un conjunto de manufacturas suntuarias dependientes del poder como eficaz y enérgico medio de promoción oficial ${ }^{5}$.

Asimilado desde antiguo en el mundo islámico oriental, el origen de este modelo de organización basado en manufacturas de lujo bajo control gubernamental se retrotrae a la Antigüedad clásica y a Bizancio. Talleres oficiales (demosia somata) produjeron preciados textiles, vestimentas, joyas, armas, monedas y piezas eborarias durante siglos para la corte de Constantinopla, al igual que anteriormente lo habían hecho las fabricae publicae en el Imperio romano ${ }^{6}$. El trabajo del marfil fue un monopolio estatal en Bizancio, pero mientras Beckwith defiende la existencia de obradores imperiales trabajando dentro del ámbito del Gran Palacio, Cutler rechaza esta posibilidad sugiriendo el probable establecimiento de un sistema de factorías bajo supervisión estatal, en el cual los artistas ejecutaban los encargos en talleres particulares. Estos se hallaban generalmente asociados a sus viviendas y, por tanto, integrados en la urbe ${ }^{7}$.

Las primeras obras en marfil de las que se tiene noticia en al-Andalus se sitúan cronológicamente en el segundo cuarto del siglo X, aunque de ellas solo conservamos referencia literaria. Nos referimos a los regalos enviados como presente diplomático por 'Abd al-Rahmān III al príncipe beréber norteafricano Mūsa b. Ab̄̄ l-Āfiya en el año 934, tan solo cinco años después de la autoproclamación de al-Nāsir como califa y de su escisión religiosa de Bagdad. Se trata de tres piezas en colmillo de elefante, dos píxides y una arqueta, descritas minuciosamente por Ibn Hayyān en el Muqtabis $V^{8}$. Un elocuente testimonio que presupone la existencia en fecha bien temprana de un taller de marfil perfectamente constituido que trabajaba para satisfacer las necesidades de la corte, estimulado al amparo de la creciente demanda de ostentación generada en torno al recién proclamado monarca. Creemos que este obrador debía estar instalado por entonces en el núcleo urbano de Córdoba, pues desde época de 'Abd al-Rahmān II funcionaba en la capital de al-Andalus un centro artesano oficial o Casa

4 M. ACIÉN ALMANSA y A. VALLEJO TRIANO, "Urbanismo y estado islámico: de Corduba a Qurtuba-Madinnat al-Zahrā'”, P. CRESSIER y M. GARCÍA ARENAL (eds.), Genèse de la ville islamique en al-Andalus et au Maghreb occidental, Madrid, 1998, p. 118.

5 Así aparece recogido en las fuentes coetáneas. Vid. IBN HAYYĀN, Crónica de los emires Alhakam Iy 'Abdarrahmān II entre los años 796 y 847 [Almuqtabis II-1], Traducción, notas e índices de M. A. MAKKI y F. CORRIENTE, Zaragoza, 2001, pp. 179-180.

6 Cfr. R. S. LOPEZ, "Silk Industry in the Byzantine Empire", Speculum, XX (1945), pp. 3-8; R. J. FORBES, Studies in Ancient Technology, Leiden, 1964, p. 56.

7 Respecto a estas dos posturas historiográficas vid. A. CUTLER, The Hand of the Master: Craftsmanship, Ivory and Society in Byzantium (9 ${ }^{\text {th }}-11^{\text {th }}$ centuries), Princeton, 1994, pp. 68 y 233.

8 "Nueve botes y cajas llenos de diversos perfumes, entre ellos un bote de plata, de forma redonda, lleno de sándalo mezclado con ámbar, un bote de marfil blanco con incienso aderezado con ámbar, otro bote de marfil también con bisagras de plata que contenía una vasija iraquí llena de excelente algalia, una tercera caja de marfil con bisagras de plata y techo plano con perfumes reales...". Vid. IBN HAYYĀN, Crónica del califa Abdarrahman III an-Nasir entre los años 912 y 942 (al-Muqtabis V), Traducción, notas e índices por M. J. VIGUERA y F. CORRIENTE, Zaragoza, 1981, pp. 264-265. 
de los Oficios, designado con el término árabe de $d \bar{a} r$ al-sinā'a, que englobaba manufacturas diversas en las que se elaboraban variados productos suntuarios: cerámica, metalistería y, casi con toda seguridad, también objetos eborarios. Acién Almansa y Vallejo Triano han localizado este complejo estatal en el extremo suroccidental de la medina, próximo a la Bāb Isbīliya (Puerta de Sevilla) ${ }^{9}$, también conocida como Bāb al-Attārìn o Puerta de los Drogueros, puesto que comunicaba con el arrabal de los perfumistas, tras del cual estaba situado el de los pergamineros ${ }^{10}$ (fig. 1).

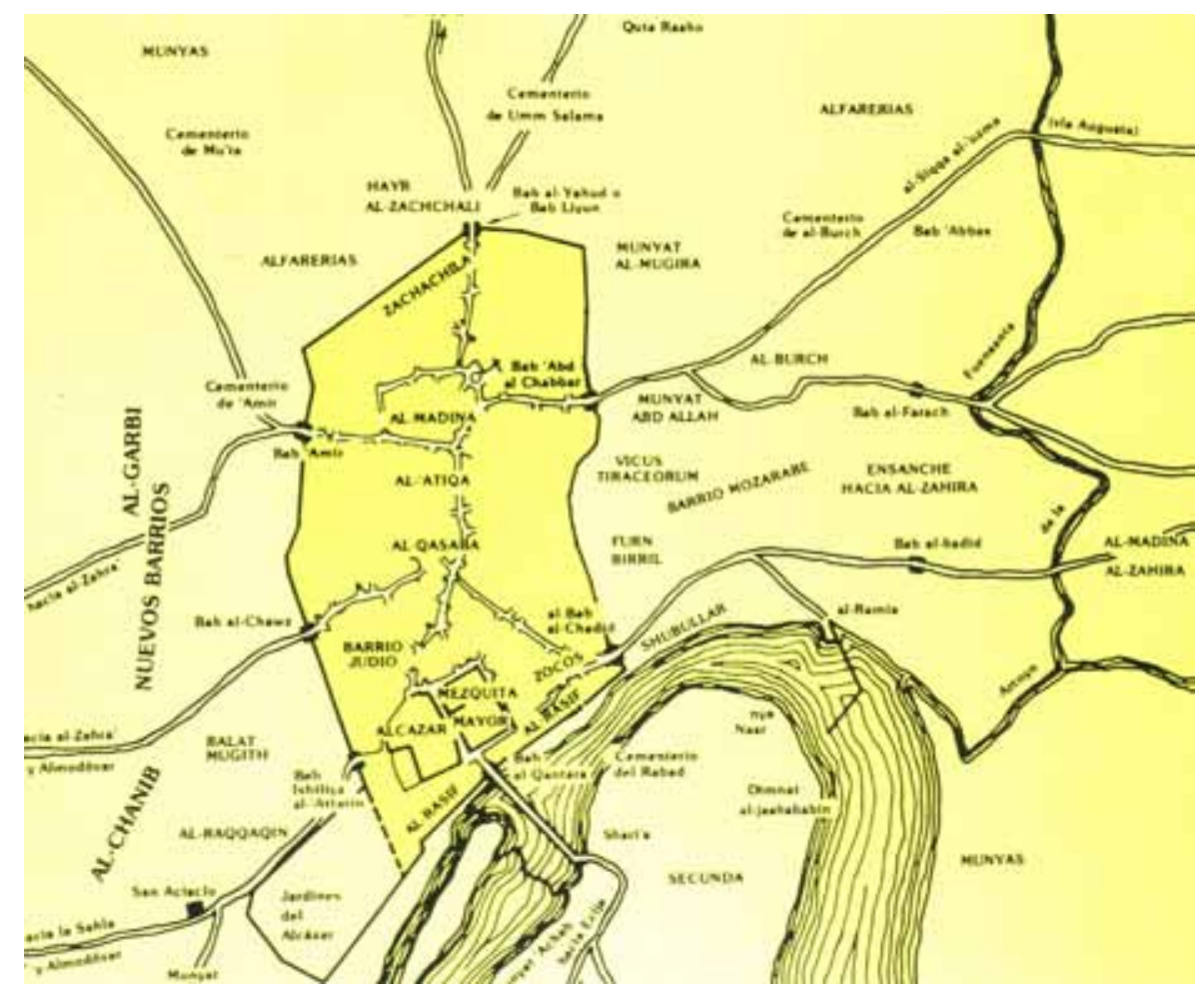

Fig. 1. Plano de la medina de Córdoba y sus barrios adyacentes en el siglo X según E. Lévi-Provençal.

El establecimiento que agrupaba las manufacturas de lujo estaba emplazado, pues, a principios de la época califal en un área muy cercana a la zona residencial y política del alcázar de los Omeyas, ocupando parte del espacio libre existente entre la suso-

9 M. ACIÉN ALMANSA y A. VALLEJO TRIANO, op. cit., 1998, p. 118, nota 67.

10 P. MARFIL RUIZ, "Córdoba de Teodosio a Abd al-Rahmán III", L. CABALLERO y P. MATEOS (eds.), Visigodos y Omeyas. Un debate entre la Antigüedad tardia y la Alta Edad Media, Madrid, 2000, p. 138. Sobre esta puerta de acceso a la medina de Córdoba en época califal, vid. M. OCAÑA JIMÉNEZ, "Las puertas de la medina de Córdoba", Al-Andalus, III (1935), pp. 144 y 150 y E. GARCÍA GÓMEZ, "Notas sobre la topografía cordobesa en 'Los anales de al-Hakam II' por Isa al-Razi”, Al-Andalus, XXX (1965), p. 349. 
dicha puerta y el muro occidental del palacio, siguiendo la costumbre oriental de que los talleres artísticos especializados se situaran en las proximidades de las residencias palatinas. Este era además el ámbito donde se concentraba la principal actividad económica y comercial de la ciudad, pues allí se encontraba también enclavado el zoco mayor $^{11}$.

A la vez, pero concebido de manera autónoma y con distinto emplazamiento, funcionaba otro taller dedicado específicamente a la producción de ricos textiles, identificado en las fuentes con el nombre de Dār al-tira $\bar{z}^{12}$, que se hallaba ubicado en los arrabales al norte de Córdoba, extramuros de la medina, y próximo al cementerio de Bāb al-Yahūd (Puerta de los Judíos) ${ }^{13}$.

Como culminación del programa político y propagandístico derivado de su recién asumida dignidad califal, 'Abd al-Rahmān III erigió al oeste de Córdoba una ciudad palatina de nueva planta que bautizó con el nombre de Madīnat al-Zahrā'. La edificación de la misma se inició según al-Maqqarī en el año 325H /936 d.C., interpretándose la fecha de 329 H /940-941 d.C. que proporciona Ibn Hayyān como la de construcción o finalización de la residencia califal (Dār al-Mulk ${ }^{14}$. Los trabajos se prolongarían aproximadamente unos veinticinco años más, hasta la muerte de alNāsir, continuando las obras durante otros quince, a lo largo del reinado de su hijo alHakam II, lo que equivale a un total de cuarenta años de trabajos ininterrumpidos. La repercusión de esta magna obra fue extraordinaria en el ámbito artístico, favoreciendo, entre otras muchas novedades, una reubicación del centro de producción eboraria.

A la recién fundada urbe, ideada como residencia oficial del califa y sede de la administración del Estado, fueron trasladados gradualmente, no solo la Casa privada del monarca y su corte, sino también la mayor parte de los servicios e instituciones que hasta ese momento habían estado localizados en la metrópoli cordobesa, con el fin de convertir al-Zahrā' en el nuevo centro de la administración del Califato andalusí. Cambiaron de asentamiento de forma progresiva los principales órganos burocráticos y administrativos, los espacios protocolarios y de representación (Secretaría de Estado, Cancillería), las sedes militares (Casa del Ejército y almacenes de pertrechos bélicos), religiosas (mezquita aljama), económicas (ceca), y también las manufactu-

11 E. GARCÍA GÓMEZ, op. cit., p. 348 y J. M. ESCOBAR CAMACHO, "Córdoba en la época califal", E. CABRERA (coord.), 'Abd al-Rahmān III y su época, Córdoba, 1991, p. 225.

12 Tirāz es una palabra de origen persa que significa "bordado". Por extensión, recibe también la denominación de tirāz el taller donde se elaboraban los tejidos. Vid. Y. K. STILLMAN y P. SANDERS, "Tirāz", Encyclopédie de l'Islam, vol. X, nouvelle édition, Leiden-París, 2002, pp. 573-578 y C. PARTEARROYO LACABA, "Los tejidos de al-Andalus entre los siglos IX al XV (y su prolongación en el siglo XVI)", España y Portugal en las rutas de la seda. Diez siglos de producción y comercio entre Oriente y Occidente, Barcelona, 1996, p. 58. Análoga denominación es empleada por Ibn Jaldún en su Introducción a la Historia Universal (Al-Muqaddima) para referirse a esta institución como uno de los emblemas de realeza. Cfr. IBN JALDÚN, op. cit., libro I, cap. III, apdo. 34, pp. 467-469.

13 M. ACIÉN ALMANSA y A. VALLEJO TRIANO, op. cit., 1998, p. 119 y A. VALLEJO TRIANO, La ciudad califal de Madinat al-Zahrā'. Arqueología de su excavación, Córdoba, 2010, p. 66. Respecto a la posible localización arqueológica de este edificio fabril, vid. infra, pp. 287-288. En torno al dār al-tirāz se configuró con el tiempo un pequeño núcleo urbano, que no aparece reseñado en la relación de arrabales de Ibn Baškuwāl, pero que sí se cita en el Calendario de Córdoba. Vid. R. DOZY, Le Calendrier de Cordoue, Leiden, 1961, pp. 73, 103 y 163.

14 A. VALLEJO TRIANO, op. cit., 2010, p. 139. 
ras estatales vinculadas a la realeza. Según informan las fuentes, en el año 335H /946 d.C. se modificó el emplazamiento de la dār al-sinā'a o centro artesano oficial, el cual debía integrar el taller especializado en la realización de objetos de marfil para uso oficial y personal del monarca y, un año más tarde, en 947 d.C., lo haría la $d \bar{a} r$ al-sikka (casa de la moneda) ${ }^{15}$.

El traslado de la ceca es confirmado casi simultáneamente por el registro numismático, pues a partir de la fecha aludida aparecen ya monedas acuñadas en la ciudad palatina ${ }^{16}$. En el caso del obrador de marfiles, sin embargo, la evidencia material del cambio de sede se retrasa algunos años respecto a la cronología que nos brindan los documentos, ya que no conservamos objetos que aludan en sus inscripciones dedicatorias al taller de marfiles del al-Zahra' hasta el año 966 d.C., como se constata en las arquetas del Instituto Valencia de Don Juan (Madrid) y del monasterio de Fitero (Navarra) ${ }^{17}$. Sin duda la demora que se advierte a la hora de registrar la nueva ubicación del taller es meramente accidental y obedece tan solo al escaso número de piezas andalusíes fabricadas en colmillo de elefante que nos han llegado, no afectando en nuestra opinión en absoluto a la veracidad de la fecha de traslado de esta industria ofrecida por los cronistas, que de seguro debió efectuarse en torno al año 946 d.C., como unidad integrante del complejo de manufacturas estatales.

La localización de estos talleres oficiales dentro del conjunto arqueológico de la ciudad palatina ha sido sugerida por Vallejo en su reciente monografía sobre Madīnat al-Zahrā' ${ }^{\prime 18}$. En su opinión, todos los indicios apuntan a que dicho establecimiento debió estar emplazado en la terraza inferior de la urbe que, desde el punto de vista de organización urbanística, acogía la medina propiamente dicha.

Dado que la excavación sistemática de al-Zahrā' se ha centrado tradicionalmente en el nivel superior, que albergaba el sector oficial y residencial del alcázar ${ }^{19}$, el conocimiento del área correspondiente a la medina resulta muy limitado, habiéndose sacado a la luz muy escasas estructuras. Sin embargo, gracias a algunos recursos, como el análisis topográfico o la interpretación de la fotografía aérea vertical, es posible llegar a conocer en buena medida cuál fue la planificación urbanística de este sector.

15 AL-MAQQARĪ, Analectes sur l'histoire et la littérature des Arabes d'Espagne, ed. por R. DOZY, G. DUGAT, L. KREHL y W. WRIGHT, vol. I, Leiden, 1855, pp. 346, 370-371 y 373.

16 A. VALLEJO TRIANO, Madīnat al-Zahra. Guía oficial del conjunto, Sevilla, 2004, pp. 17-18.

17 N. SILVA SANTA-CRUZ, "Nuevos datos para el estudio de dos piezas de eboraria califal: arquetas de la iglesia parroquial de Fitero y del Instituto Valencia de Don Juan", Anales de Historia del Arte, 9 (1999), pp. 27-33; Á. GALÁN Y GALINDO, Marfiles medievales del Islam, Córdoba, 2005, vol. I, pp. 177-189 y 437; vol. II, pp. 26-30.

18 A. VALLEJO TRIANO, op. cit., 2010.

19 A fines de los años ochenta, Acién valoraba la parte excavada aproximadamente en un 10 o $15 \%$ de la superficie total del recinto. Vid. M. ACIÉN ALMANSA "Madīnat al-Zahrā' en el urbanismo musulmán", Cuadernos de Madinnat al-Zahrā', 1 (1987), p. 18. En 2007, Vallejo afirmaba que el área recuperada apenas había variado, siendo básicamente la misma que había quedado establecida dos décadas antes, circunscrita al sector central del alcázar, con una superficie aproximada de unas 10 ha. del total de 112 ha. que comprenden la extensión global de la ciudad. Vid. A. VALLEJO TRIANO "Madīnat al-Zahrā'. Notas sobre la planificación y transformación del palacio", Artigrama, 22 (2007), p. 73. En 2012 el porcentaje excavado no se ha ampliado notablemente. 
Vallejo ha identificado en esta tercera terraza, la de cota más baja, una amplia extensión sin edificar que ocupaba toda la parte central de la ciudad, desde el límite sur de los jardines alto y bajo hasta la muralla meridional, constituyendo una gran superficie que ocupaba todo el frente del primitivo alcázar, reservada probablemente para usos agrícolas o de ocio ${ }^{20}$. Este espacio no urbanizado estaba flanqueado por dos ámbitos edificados, uno occidental, de forma alargada paralelo a la muralla, y otro más amplio en la zona oriental.

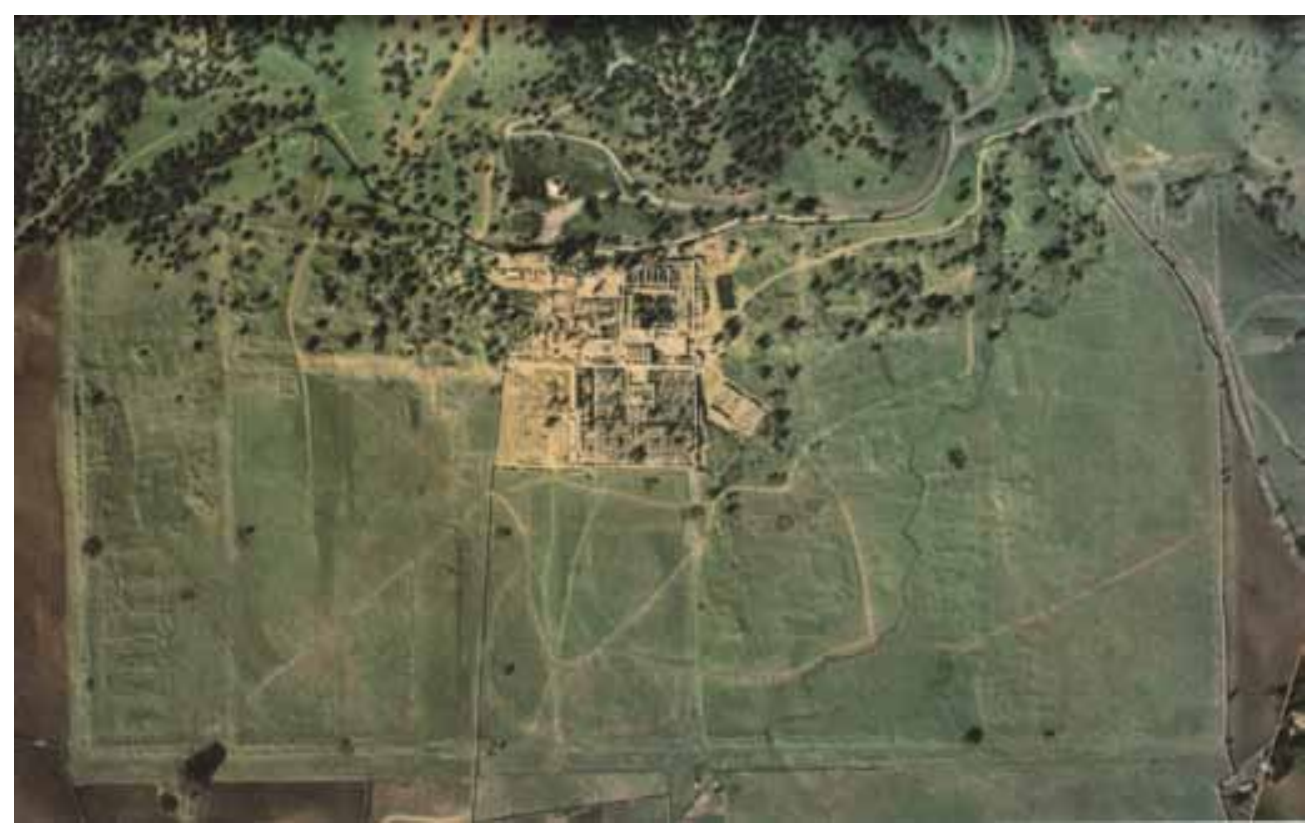

Fig. 2. Fotografía aérea vertical de la ciudad palatina de Madīnat al-Zahrā', según A. Vallejo Triano.

El sector oriental, presidido por la mezquita aljama, constituyó un área residencial, donde debió asentarse la población común de la ciudad, formada por mercaderes, artesanos, etc., y parece que tal vez también por visires, nobles y altos funcionarios ${ }^{21}, \mathrm{y}$ donde se localizaría el zoco y otras edificaciones urbanas, tales como algunas pequeñas mezquitas de barrio ${ }^{22}$. La franja oeste se reservó, en cambio, para las construcciones oficiales. Aunque no han sido excavadas por el momento, la fotografía aérea permite identificar la existencia de seis grandes estructuras idénticas, contiguas y ali-

20 En este lugar debió situarse tal vez el zoológico o recinto para animales exóticos al que se refiere alMaqqarī y un campo para entrenamiento hípico. Vid. A. VALLEJO TRIANO, op. cit., 2010, pp. 181-182.

21 Según Ibn Gālib, "También los visires, nobles y altos funcionarios tenían sus casas a levante de la ciudad", vid. J. VALLVÉ BERMEJO, "La descripción de Córdoba de Ibn Gālib", Homenaje a Pedro Sainz Rodríguez, vol. III: Estudios históricos, Madrid, 1986, p. 674.

22 A. VALLEJO TRIANO, op. cit., 2010, pp. 133 y 186. 
neadas de norte a sur, que corresponden sin duda a un importante conjunto de inmuebles de carácter estatal (fig. 2). Por su similitud con organizaciones conservadas en Samarra, estos pabellones pudieron albergar el asiento de la guarnición militar de la ciudad palatina, aunque también se ha sugerido que acogieran el conjunto de talleres artísticos dependientes del Estado califa ${ }^{23}$. Una hipótesis probable, ya que las fuentes árabes sitúan este centro artesano oficial exactamente "a los lados de al-Zahra"24, en algún lugar de esta franja urbanizada occidental, junto con el edificio destinado a la ceca $^{25}$. Asimismo, si atendemos a la información proporcionada por Ibn Gālib, también en la zona oeste, próximo a estas industrias, residiría el personal que las atendía y supervisaba ${ }^{26}$. Entre ellos también, suponemos, los artífices eborarios.

Como ha señalado Vallejo con gran acierto, en Madīnat al-Zahrā' se reproduce la misma topografía urbana que veíamos en Córdoba desde época emiral, donde el conjunto de la dār al-sinā' $a$ se encontraba instalado a poniente del alcázar omeya ${ }^{27}$. El tira $\bar{z}$, en cambio, no parece cambiar de emplazamiento ante los nuevos acontecimientos políticos, manteniéndose asentado durante el período califal en el área periurbana septentrional de la capital andalusíi ${ }^{28}$. Su situación puede deducirse con bastante precisión a partir de la noticia recogida por el historiador Ibn Hayyān en su Muqtabis, que relata la visita efectuada a las instalaciones del obrador textil por al-Hakam II en septiembre del año 972, quien, para llegar hasta el arrabal donde se hallaba el complejo, hubo de salir por la Puerta de los Judíos (Bāb al-Yahüd) y pasar por el cementerio de Umm Salama ${ }^{29}$. Se ha propuesto su posible localización arqueológica al norte de los terrenos de la antigua estación de ferrocarril de Córdoba, próximo al yacimiento tardorromano de Cercadilla, cuya aula septentrional fue reutilizada como lugar de culto cristiano (iglesia-convento de San Zoilo) ${ }^{30}$. En esa ubicación fueron excavados en 1991, durante la construcción del Tren de Alta Velocidad (AVE), los cimientos de un edificio de enormes dimensiones al que se atribuyó un carácter eminentemente

23 Ibídem, pp. 132-133 y 185.

24 Según relata al-Maqqarī, una delegación de embajadores bizantinos llegados a al-Zahra' en el año 949, "visitaron la dar al-sina'a y la dar al 'udda (la casa de los oficios y la casa de los equipos militares), a los lados de al-Zahra', y la dar al-sikkka (casa de la moneda)". vid. R. CASTEJÓN CALDERÓN, "Madīnat alZahrā' en los autores árabes", Al-Mulk. Anuario de Estudios Arabistas, 2 (1961-1962), p. 137. Citado en A. VALLEJO TRIANO, op. cit., 2010, p. 184.

25 A. VALLEJO TRIANO, op. cit., 2010, p. 185.

26 'Las casas de los jóvenes o fatàs eslavos, de los esclavos, de gran parte de los soldados de al-Zahra' y de los funcionarios estaban fuera del Alcázar, por la parte de poniente", vid. J. VALLVÉ BERMEJO, op. cit., 1986, p. 674.

27 A. VALLEJO TRIANO, op. cit., 2010, p. 185.

28 Ibídem,, pp. 66 y 185; M. ACIÉN ALMANSA y A. VALLEJO TRIANO, op. cit., 1998, p. 119.

29 "El sábado día 24 de $d \bar{u}-l-q a$ 'da de ese año [=6 de septiembre 972] fue el Califa a caballo a la Dār alTirāz. Al entrar en ella fue recibido por los directores administrativos y por los directores de los talleres, que le rindieron el debido acatamiento. El Califa les pidió detalles de su trabajo y les favoreció con sus indicaciones. El camino del Califa, a la ida, había sido por el cementerio de la Bāb al-Yahūd, que toma el nombre de Umm Salama, (...)". Vid. A. ARJONA CASTRO, Anales de la Córdoba musulmana (711-1008), Córdoba, 1982, p. $159, \mathrm{n}^{\circ} 203$.

30 A. ARJONA CASTRO y P. MARFIL RUIZ, "Posible localización de los restos arqueológicos del Dār al-Tirāz (Casa del tiráz) en la Córdoba musulmana", Boletín de la Real Academia de Córdoba de Ciencias, Bellas Letras y Nobles Artes, 147 (2004), p. 140. 
público, el cual sería reexcavado en una segunda fase (1997-1998) al edificar en sus inmediaciones un aparcamiento subterráneo ${ }^{31}$.

Es, por tanto, hacia mediados del siglo X, coincidiendo con el cambio de capitalidad, cuando se altera por primera vez el emplazamiento del complejo eborario califal, que abandona el centro de Córdoba, para instalarse en la ciudad palatina de Madīnat al-Zahrā'. A partir de ese momento, y gracias al impulso oficial, este taller de marfiles llegará a ser una de las principales manufacturas áulicas de todo el Occidente medieval, dado el refinamiento y la altísima calidad de sus ejemplares, convirtiéndose durante algunas décadas en la principal fuente de abastecimiento de piezas elaboradas en colmillo de elefante en el territorio de al-Andalus, así como en el foco donde se gestarán las más relevantes novedades iconográficas y decorativas. Desafortunadamente, las noticias documentales directas relativas a esta manufactura son inexistentes. Sospechamos que el vacío de información que se desprende de la lectura de las fuentes históricas y literarias hispano-árabes podría tener que ver con una circunstancia muy concreta ligada a la propia naturaleza de la manufactura, pues, casi con total seguridad, y a diferencia del tirāz, el centro de producción de marfiles nunca debió independizarse por completo del conjunto de talleres artísticos estatales, conformando siempre un núcleo compacto con ellos.

Los productos salidos de esta industria eboraria de lujo, y del resto de manufacturas estatales, constituían monopolios exclusivos del Estado omeya ${ }^{32}$, estando prohibida su venta, como sucedía también en Bizancio ${ }^{33}$. Al ser prerrogativa regia, se reservaban para el uso particular del soberano, ya fuera en su vida privada o en ceremonias oficiales. Asimismo servían como regalos o presentes de honor (jil'a) ${ }^{34}$ dentro del complejo universo de sus relaciones cortesanas y diplomáticas, constituyendo signos externos de su generosidad, favor, privanza o amistad ${ }^{35}$. De declarar la noble procedencia de estos objetos se encargaban no solo la excelente calidad de la materia prima y una esmerada ejecución, sino también la escritura. La grafía árabe, desplegada siempre en lugares bien visibles sobre la superficie de los ejemplares, adoptaba una función eminentemente promocional, al incluir textos conmemorativos que, además de eulogias o frases de alabanza, contenían en muchos casos referencia directa al soberano como comitente o destinatario de las piezas ${ }^{36}$, recurriendo siempre a un formulario fijo y estereotipado. Estos epígrafes actuaban como un marchamo real ${ }^{37}$, una especie de sello de calidad que vinculaba estas manufacturas sin posibilidad alguna de error con la producción palatina y la institución califal.

31 Ibidem, p. 141; P. MARFIL RUIZ, op. cit., 2000, p. 122; M. ACIÉN ALMANSA y A. VALLEJO TRIANO, op. cit., 1998, p. 119.

32 S. CALVO CAPILLA, "Viajes por el Mediterráneo entre los siglos VIII-XII: tras los pasos de los viajeros andalusíes, fatimíes y bizantinos", M. CORTÉS ARRESE (coord.), Caminos de Bizancio, Cuenca, 2007, p. 168.

33 A. VASILIEV, History of the Byzantine Empire, 324-1453, Madison, 1958, vol. I, p. 168.

34 X. BALLESTÍN NAVARRO, "Jil'a y monedas: el poder de los Banū Marwān en el Magrib al-Aqsā”, Al-Qantara, XXVII, 2 (2006), p. 398.

35 M. A. MARTÍNEZ NÚNEZZ, op. cit., 1999, p. 139.

36 Ibídem.

37 Ibídem, p. 151. 
Por su valor simbólico y propagandístico en relación con el poder, estos objetos suntuarios estaban sometidos a un estricto control estatal a lo largo de su proceso de fabricación, que implicaba una precisa organización burocrática y artística. La labor de dirección representativa era ejercida por un delegado del califa, encargado de comisionar nominalmente los trabajos desde su puesto de funcionario público en la administración omeya. Este personaje de alto rango, ocuparía la supervisión honorífica de los talleres de marfil, representando de forma simbólica la cúspide en la estructura jerárquica de producción. Su nombre se incluye en algunas de las piezas de marfil tras la expresión árabe 'alà yaday ("bajo la dirección de...") ${ }^{38}$. Sobre él recaería la máxima jurisdicción sobre los productos salidos del taller eborario estatal, al ejercer una función de vigilancia o "alta inspección" nominal sobre los mismos. A pesar de la escasa información de que disponemos, todo apunta a que este sobresaliente empleado palatino no asumiría decisiones concretas de carácter artístico en relación con los productos eborarios, sino que ejercería una función básicamente de representación de la institución califal. Según Martínez Núñez, bajo su autoridad se situarían los ashāb o directores de la dār al-sinā' $a$ califal, intendentes específicos de cada taller especializado, que ejercerían ya no como dirigentes honoríficos, sino como directores efectivos o directores técnicos, asumiendo la auténtica función de control, coordinación o jefatura sobre la labor realizada por los artesanos. Es decir, en ellos se delegaría la supervisión directa del trabajo de los maestros ${ }^{39}$.

Los breves textos conmemorativos que incorporan la píxide de Zamora (Museo Arqueológico Nacional, Madrid, inv. $\left.\mathrm{n}^{\mathrm{o}} 52.113\right)^{40}$ y la caja calada dedicada al califa al-Hakam II (Victoria \& Albert Museum, Londres, inv. $\left.n^{\circ} 217 / 1865\right)^{41}$ en la base de sus cubiertas (figs. 3 y 4), nos brindan el nombre del relevante empleado oficial bajo cuya dirección honorífica se encontraban los talleres de marfil palatinos en el momento de la ejecución de estas piezas, mencionándolo expresamente tras la citada locución 'alà yaday. Ambas inscripciones hacen referencia al mismo sujeto: Durrī alSagīr, llamado también Durrī "el Chico" o "el Pequeño", un personaje bien conocido en las fuentes escritas coetáneas. Ibn Hayyān lo cita repetidamente en el Muqtabis desempeñando hacia los años 972-973, en una fecha relativamente cercana a la de la elaboración del recipiente zamorano (964), el destacado cargo de tesorero (al-hazin) y gran fatà del monarca al-Hakam II ${ }^{42}$.

38 Tanto Ocaña como Martínez Núñez equiparan este cargo dentro del ámbito de la arquitectura con el sāhib al-abniya (director de obras estatales). Cfr. M. OCAÑA JIMÉNEZ, "Arquitectos y mano de obra en la construcción de la Gran Mezquita de Occidente", Boletín de la Real Academia de Córdoba de Ciencias, Bellas Letras y Nobles Artes, 102 (1981), pp. 105-106; M. A. MARTÍNEZ NÚÑEZ, "La epigrafía del Salón de 'Abd al-Rahmān III", Madīnat al-Zahrā': El Salón de 'Abd al-Rahmān III, Córdoba, 1995, pp. 140-142; Ibídem, "Epígrafes a nombre de al-Hakam en Madīnat al-Zahrā”", Cuadernos de Madīnat al-Zahrā', IV (1999), p. 90.

39 Ibidem, op. cit., 1995, p. 144; Ibidem, op. cit., 1999, p. 90.

40 Á. GALÁN Y GALINDO, op. cit., 2005, vol. I, p. 437; vol. II, pp. 22-26.

41 Ibídem, vol. II, pp. 20-22.

42 IBN HAYYĀN, El Califato de Córdoba en el "Muqtabis" de Ibn Hayyān. Anales palatinos del califa de Córdoba al-Hakam II, por Isa ibn Ahmad al-Razi (360-364H. = 971-975 J.C.), trad. de E. GARCÍA GÓMEZ, Madrid, 1967, pp. 48-50, 132 y 136-137. Más noticias sobre este personaje en S. S. BLAIR, "What the Inscriptions Tell Us: Text and Message on the Ivories from Al-Andalus", K. FOLSACH, y J. MEYER (eds.), Journal of the David Collection. The Ivories of Muslim Spain. Papers from a symposium held in 


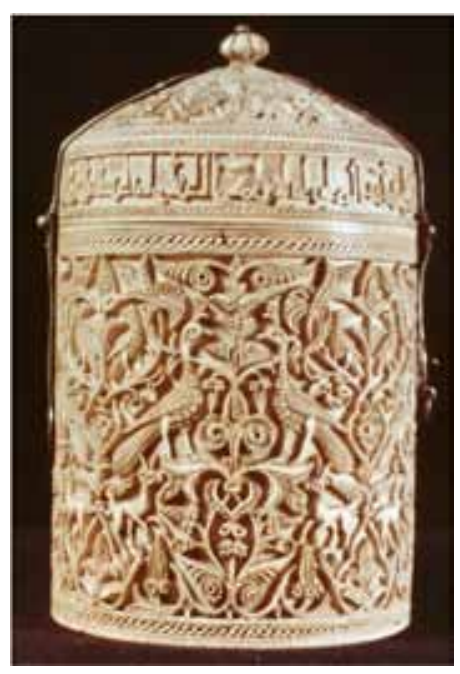

Fig. 3. Píxide de la catedral de Zamora, Museo Arqueológico Nacional, Madrid, año 964.

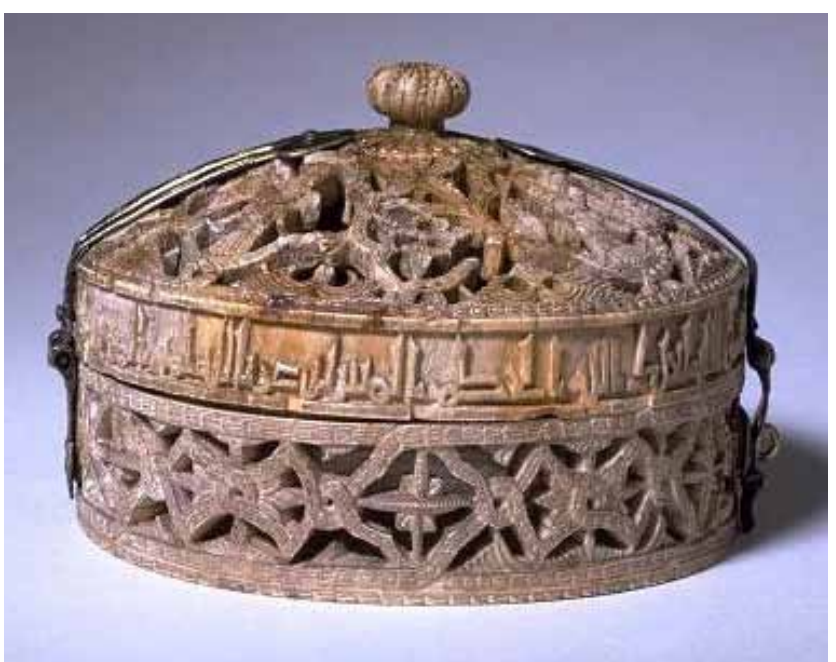

Fig. 4. Caja calada del califa al-Hakam II, Victoria \& Albert Museum, Londres, h. 970-976.

El vocablo fatà (pl. fityān) se empleaba en la España islámica para designar a los esclavos o manumitidos domésticos del califa, eunucos o no, que ocupaban la más alta posición en la jerarquía palatina, y que llegaron a desempeñar en al-Andalus un importante rol político ${ }^{43}$. Simultáneamente se utilizaba también para hacer referencia a estos servidores el término jalīfa ${ }^{44}$. Como señala el cronista Ibn Hayyān ${ }^{45}$, por encima del conjunto general de los fityān sobresalían ciertos individuos de mayor categoría, designados como fatà al-kabir o gran fatà, que ejercían el cargo de "gran oficial" en diferentes áreas administrativas.

Además de actuar como fatà al-kabir, el empleado oficial de alto nivel al que nos acabamos de referir era miembro de los Banu Durrī, una influyente familia de ascendencia eslava que proveyó a la administración califal de destacados funcionarios ${ }^{46}$. Dos de estos dignatarios, con idéntico nombre de pila, se citan repetidamente en las

Copenhagen from the $18^{\text {th }}$ to the $20^{\text {th }}$ of November 2003, vol. 2, 1, Copenhague, 2005, p. 86. Recientemente G.D.ANDERSON, "Concubines, Eunuchs, and Patronage in Early Islamic Córdoba", T. MARTIN (ed.), Reassessing the Roles of Women as Makers of Medieval Art and Architecture, vol. II. Brill, 2012, pp. 633669, espec. 653-656.

43 Cfr. F. MAÍllo SAlgado, Crónica anónima de los Reyes de Taifas. Madrid, 1991, p. 23, nota 16.

44 Ibídem, p. 42, nota 73 e IBN 'IDĀRĪ, La caída del Califato de Córdoba y los Reyes de Taifas (al-Bayan al-mugrib), Estudio, traducción y notas por F. MAÍLLO SALGADO, Salamanca, 1993, p. 17, nota 34. Véase también S. S. BLAIR, op. cit., 2005, p. 86.

45 IBN HAYYĀN, op. cit., 1967, p. 49

46 En relación con esta familia vid. M. MEOUAK, "Deux familles d'origene 'affranchie' au service de L'Etat hispano-umayyade: les Banū Durrī et Banū Tarafa", Anaquel de Estudios Árabes, 2 (1991), pp. 186188; Ibídem, Pouvoir souverain, administration centrale et élites politiques dans l'Espagne umayyade (IIe-IVe / VIIIe-Xe siècles), Helsinki, 1999, pp. 199-200 y 215-216. 
fuentes. Hasta entonces confusos, han sido identificados por Meouak como miembros pertenecientes a dos generaciones sucesivas de este linaje ${ }^{47}$. El funcionario de mayor edad citado en las fuentes, desempeñó cargos de gran responsabilidad bajo 'Abd al-Rahmān III ${ }^{48}$. Nuestro Durrī, en cambio, seguramente hijo del anterior, como proponen Arnold, Canto y Vallejo ${ }^{49}$, trabajó para al-Hakam II, incorporando a su onomástica el laqab o apodo "as-Sagīr" ("el Pequeño" o "el Chico") para ser distinguido con facilidad de su progenitor dentro del círculo administrativo y cortesano.

$\mathrm{Al}$ igual que muchas otras autoridades del Estado omeya andalusí, ambos eran de origen eslavo. El término genérico "eslavo", en árabe saqlab o saqlabi (pl. saqāliba), fue adoptado en la España islámica durante el período califal para designar a los esclavos extranjeros, de origen europeo, alistados en las milicias o encargados de los servicios palatinos ${ }^{50}$. Haciendo uso de sus dotes naturales, muchos de ellos llegaron a ocupar importantes puestos en la administración ${ }^{51}$. Algunos, incluso, fueron prohijados por los propios califas, lo que les permitía recibir el nombre del soberano a modo de apellido, como sucedió con el general Gālib, hijo adoptivo de 'Abd al-Rahmān III ${ }^{52}$ o el propio Durrī el Chico, al que la documentación epigráfica nombra con la nisba de al-Hakam II, evidenciando su estrecha relación con éste ${ }^{53}$.

Exceptuando los destinados a ocupaciones militares, la mayoría solían ser castrados. Procedían habitualmente del litoral del Mar Negro, en concreto de los territorios limítrofes con los kázaros, entre Constantinopla y el país de los búlgaros. Con frecuencia estos individuos eran hechos cautivos por los ejércitos germánicos durante

47 Ibídem.

48 Fue encargado del alarde en el año 913, desempeñó el cargo de sahib al-surta entre 920-929 y lideró importantes campañas militares, como la represión de los beréberes de Nafza en Talavera en 936 (M. MEOUAK, op. cit., 1991, pp. 186-187). Aparece mencionado además como supervisor del taller de tejidos reales en la inscripción del tirāz bordado de 'Abd al-Rahmān III, que actualmente se conserva en el Museum of Art de Cleveland (inv. $\mathrm{n}^{\circ}$ 1977.188), datado hacia el 941-942. Vid. C. PARTEARROYO LACABA, "Tejidos andalusíes", Artigrama, 22 (2007), p. 380.

49 F. ARNOLD, A. CANTO GARCÍA y A. VALLEJO TRIANO, "La almunia de al-Rummaniyya. Resultados de una documentación arquitectónica", Cuadernos de Madinat al-Zahra, 6 (2008), pp. 183-184.

50 K. SATO, "Slave elites and the Saqaliba in al-Andalus in the Umayyad period", T. MIURA y J. PHILIPS (eds.), Slave elites in the Middle East and Africa, Londres, 2000, pp. 25-40 e Ibidem, "Los saqaliba y la corte en la segunda mitad del siglo X", A. TORREMOCHA SILVA y V. MARTÍNEZ ENAMORADO (eds.), Al-Andalus y el Mediterráneo en torno al año 1000. La época de Almanzor, Algeciras, 2003, pp. 108-115; M. MEOUAK, Saqaliba: eunuques et esclaves à conquête du pouvoir. Helsinki, 2004. Los esclavos de raza blanca de procedencia europea recibían una educación y formación muy esmeradas, ya que estaban destinados a ocupar altos cargos de la administración y del ejército, llegando a detentar gran poder y responsabilidad. Constituían un grupo privilegiado frente a los esclavos negros africanos ( 'abid), de segunda clase. Vid. F. VIDAL CASTRO, "La herencia de Almanzor: Al-Andalus bajo las dinastías y las "clases" "amiríes", A. TORREMOCHA SILVA y V. MARTÍNEZ ENAMORADO (eds.), Al-Andalus y el Mediterráneo en torno al año 1000. La época de Almanzor, Algeciras, 2003, p. 128.

51 Al controlar importantes cargos en la administración, los eslavos intervinieron de forma directa en la caída del Califato. Junto con árabes y muladíes, formaron un frente común en contra de los beréberes norteafricanos, siendo los responsables de la creación de varios reinos de taifas en la costa levantina. El más destacado fue el rey de Denia, Muŷahid, conquistador de las Islas Baleares y Cerdeña. Vid. J. VALLVÉ BERMEJO, "La herencia del Califato de Córdoba", Los Reinos de Taifas: Un siglo de oro en la cultura musulmana, Madrid, 1997, p. 27.

52 M. MEOUAK, op. cit., 1999, p. 212.

53 Ibidem, p. 215. 
sus expediciones militares, siendo con posterioridad revendidos a los musulmanes de la Península. No obstante, algunos provenían de lugares menos distantes, como Calabria, Lombardía, Cataluña o Galicia ${ }^{54}$.

Su número llegó a ser muy elevado en la corte califal, incrementándose significativamente bajo 'Abd al-Rahmān III ${ }^{55}$. Lévi Provençal estima que a fines del reinado de an-Nāsir, la cifra de los saqāliba del palacio de Madīnat al-Zahrā' ascendía a $3.750^{56}$. Solían ser bastante jóvenes cuando llegaban a territorio de al-Andalus, por lo que rápidamente aprendían la lengua árabe, convirtiéndose al Islam ${ }^{57}$. Constituyeron una categoría social que desempeñó un destacado papel en la sociedad cordobesa al manifestarse, a partir de mediados del siglo X, como la principal -por no decir casi exclusiva- fuente de suministro de personal doméstico palatino para el servicio del califa y de las grandes familias de la oligarquía árabe. Su habitual condición de eunucos les permitió encargarse de la dirección y buen funcionamiento del harem, sirviendo de intermediarios entre las mujeres, que vivían aisladas en este ámbito íntimo de la corte, y el mundo exterior ${ }^{58}$. Se encargaban además de la administración de los asuntos privados y domésticos del soberano, desempeñando algunos de ellos cargos relacionados con el mantenimiento de la vida cortesana, vinculados exclusivamente al monarca, como gran halconero (sahīb al-bayāzir), director del tirāz (sahīb al-tirāz) o director del taller de joyería (sahīb al-sāga) ${ }^{59}$. Los favoritos del soberano llegaron a convertirse en mawālì (singular mawlà), término que significa "los vinculados", ligándose a los monarcas por el sistema de clientela, lo que les permitía participar en notorios asuntos de Estado, tales como redactar documentos diplomáticos, recibir emisarios extranjeros, trasladar órdenes de los monarcas a las provincias o dirigir proyectos de obras públicas ${ }^{60}$.

Como ya se ha señalado, dentro de la estricta jerarquía palatina, estos sirvientes foráneos de origen europeo se hallaban bajo la autoridad efectiva de varios superiores, igualmente eslavos, que eran designados con el apelativo de fatà al-kabir o gran oficial, los cuales actuaban como una especie de mayordomos, jefes de la casa civil del califa, responsables del perfecto orden del conjunto complejo y superpoblado del palacio, que además compartían el mando de la guardia personal del príncipe $(\text { da 'ira })^{61}$. Como parece evidenciar la incorporación de este título formando parte de inscripciones conmemorativas sobre objetos suntuarios, como la que ostenta el bote de Zamora o la caja calada de al-Hakam II, sus atribuciones debieron hacerse extensivas también a la supervisión nominal y a la máxima jurisdicción honorífica de los talleres áulicos.

54 É. LÉVI PROVENÇAL, L'Espagne musulmane au Xème siècle. Institutions et vie sociale, París, 1932 , pp. 28-29 y 53-54.

55 S. S. BLAIR, op. cit, 2005, p. 86.

56 É. LÉVI PROVENÇAL, op. cit., 1932, p. 53. Otros autores árabes proporcionan cifras aún más elevadas, como 6.087 e incluso 13.750 saqāliba. Vid., M. MEOUAK, op. cit, 1999, p. 203.

57 É. LÉVI PROVENÇAL, op. cit., 1932, pp. 28-29.

58 K. SATO, op. cit., 2003, pp. 111-112.

59 Ibídem, p. 112.

60 Ibidem, pp. 112-113.

61 É. LÉVI-PROVENÇAL, op.cit., 1932, p. 54. 
Según narra Ibn Hayyān en el Muqtabis, en abril del año 973 el gran fatà Durrī, tesorero eslavo, cayó en desgracia ante el califa al-Hakam II por una deficiencia en el servicio, vinculada parece con el mal desempeño de sus tareas, lo cual determinó su cese y la reducción de su sueldo, ordenándosele abandonar Madīnat al-Zahrā' y trasladarse al alcázar de Córdoba ${ }^{62}$. La crónica recoge también la noticia de que, poco después, en mayo del mismo año, probablemente para ganarse el favor real, Durrī obsequió al califa con una almunia que poseía en Guadarromán, sumando a dicho regalo todos los bienes que en ella se contenían ${ }^{63}$. Al-Hakam II le nombró administrador de la finca, y en calidad de tal, organizó en ella una espectacular fiesta el 13 de mayo de 973, que agradó sobremanera al soberano. En agosto, fue perdonado por el monarca gracias a la intervención en su favor del joven príncipe Hishām, siéndole devueltos íntegros sus cargos ${ }^{64}$. Según Dozy, tras la subida al poder de Hishām II (976), este personaje fue designado gobernador de Baeza, muriendo ese mismo año asesinado por orden de Almanzor, al considerarlo el hâŷib involucrado en la agitación eslava que desencadenó la revolución cordobesa ${ }^{65}$.

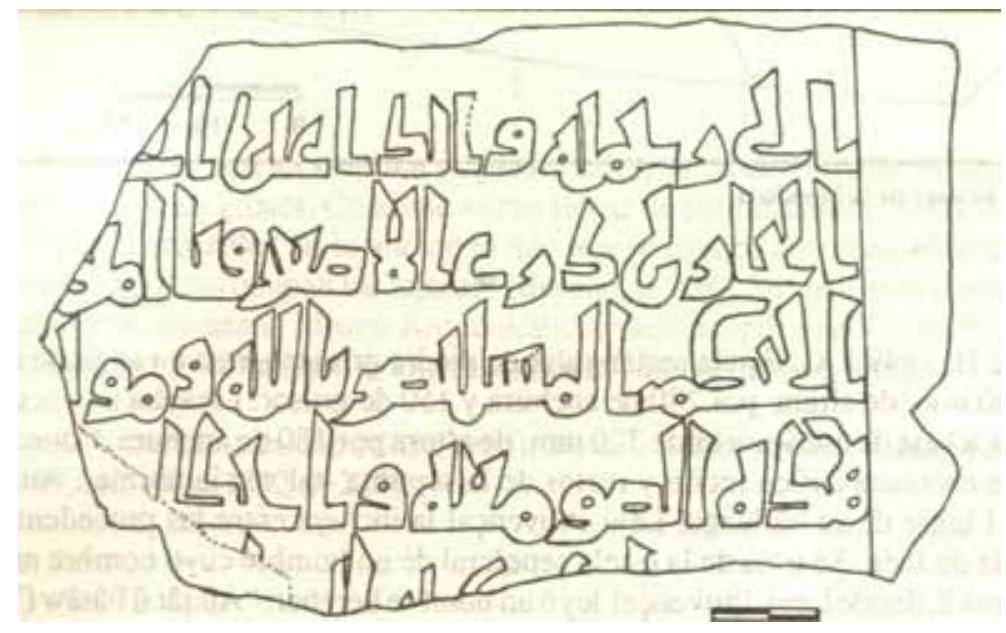

Fig. 5. Fragmento de una placa rectangular de piedra, h. 965-976, colección particular (antiguamente en el Museo de Baeza), dibujo según A. Labarta.

62 IBN HAYYĀN, op. cit., 1967, p. 132.

63 Ibídem, pp. 136-137. Esta residencia rural fue identificada por Manuel Ocaña Jiménez con la almunia alRummāniyya, correspondiente a su vez con los restos excavados parcialmente en 1910 por Ricardo Velázquez Bosco en El Moroquil. Se trata de una residencia de recreo ubicada alrededor de 10 kilómetros al oeste de Córdoba, emplazada en la ladera de la sierra, y con una organización en terrazas similar a la de Madīnat al-Zahrā'. Vid. F. ARNOLD; A. CANTO y A. VALLEJO, op. cit., 2008, pp. 181-197; Véase asimismo R. VELÁZQUEZ BOSCO, Medina Azzahra y Alamiriya, Madrid, 1912; M. OCAÑA JIMÉNEZ, "Las ruinas de 'Alamiría', un yacimiento arqueológico erróneamente denominado", Al-Qantara, V (1984), pp. $365-381$ y A. VALLEJO TRIANO, op. cit., 2010, pp. 75-78.

64 IBN HAYYĀN, op. cit., 1967, pp. 136-137.

65 Cfr. R. DOZY, Historia de los Musulmanes de España, Madrid, 1984, t. III, pp. 125-126. 
Conocemos un dato más concerniente a este servidor regio que le vincula de nuevo con la dirección honorífica de obras artísticas. Sobre una placa rectangular de piedra encontrada en la villa de Baeza (fig. 5), se conserva una inscripción fundacional mutilada procedente de un alminar que informa que la edificación del mismo fue supervisada honoríficamente por Durrī el Chico ${ }^{66}$. El epígrafe ha sido datado por Labarta entre los años 961-976, en una fecha cercana a la de las dos piezas califales de marfil de las que venimos hablando, si bien creemos que su cronología debería precisarse más acertadamente en torno a la última fecha, coincidiendo con el alejamiento de Córdoba de este personaje y con su gobierno de la localidad jienense como representante del poder central, donde su nombre sería incluido con carácter representativo en la supervisión de obras arquitectónicas de patrocinio regio como delegado del califa, probablemente cuando ya había dejado de ejercer la alta inspección nominal de piezas en marfil en el taller de al-Zahrā'.

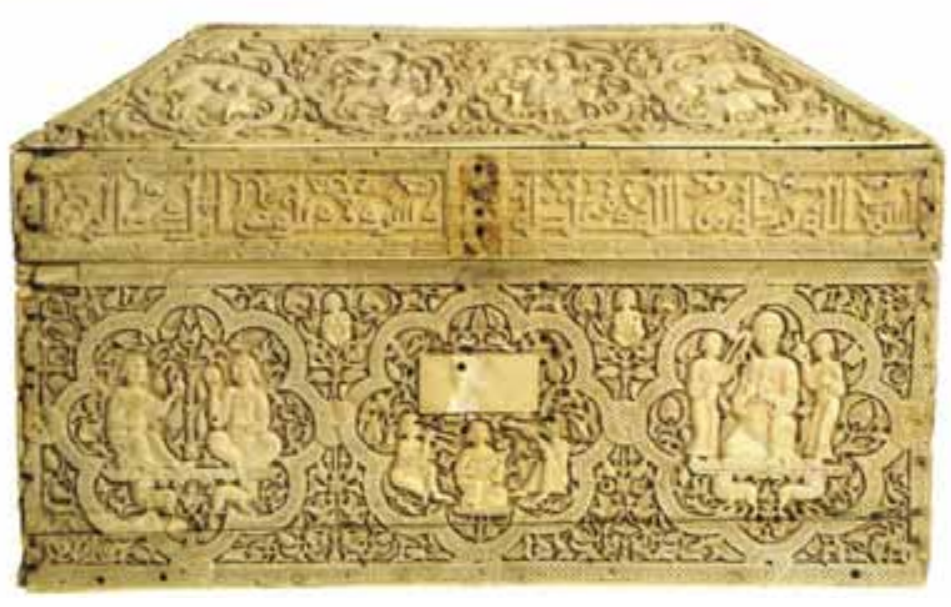

Fig. 6. Arqueta del monasterio de Leyre, Museo de Navarra, Pamplona, año 1004-1005.

Las referencias documentales que nos proporcionan las fuentes acerca de la figura histórica del burócrata Durrī al-Sagīr son de gran provecho para la investigación artística, pues favorecen el acercamiento al desconocido ámbito de la organización productiva eboraria en al-Andalus en época califal. Al mismo tiempo, permiten vislumbrar que la alta dirección honorífica de este monopolio regio estuvo durante el gobierno Omeya en manos de un alto dignatario que ocuparía el cargo de fatà alkabir o gran oficial, quien, además de otras funciones administrativas, reunía en sus

66 A. FERNÁNDEZ PUERTAS, "Dos lápidas aparecidas en la provincia de Jaén”, Al-Andalus, 41:1 (1976), pp. 213-220; A. LABARTA, "Las lápidas árabes de la provincia de Jaén”, Homenaje a Manuel Ocaña Jiménez, Córdoba, 1990, p. 128, nº 6. 
manos el control nominal de esta manufactura y, tal vez, simultáneamente el de otras especialidades artesanales de lujo.

La elección de un gran fatà, representante destacado de la administración califal, como supervisor de las piezas suntuarias en marfil producidas en la corte cordobesa, posee un destacado valor simbólico y subraya el carácter de los objetos eborarios como emblemas de poder. En época amirí se perpetuaría asimismo esta práctica, como corroboran la arqueta de Leyre ${ }^{67}$ y la píxide conservada actualmente en la Seo de Braga (Portugal) ${ }^{68}$ (fig. 6). Ambos contenedores de lujo fueron fabricados bajo la dirección honoraria de un funcionario áulico llamado Zuhayr b. Muhammad alAmirí, que a la sazón, y según nos indican las textos coetáneos, ejercía asimismo el cargo de gran oficial, pues está documentado como uno de los siete fatà al-kabir del palacio de Madīnat al-Zāhira, la nueva sede del taller estatal de eboraria en época de Almanzor.

67 Á. GALÁN y GALINDO, op. cit., 2005, vol. I, pp. 438-439 y vol. II, pp. 48-52.

68 Ibídem, vol. II, pp. 53-55. 